\title{
Prevalence of Coaching and Approaches to Supporting Coaching in Education
}

Kasey Van Ostrand, John Seylar, Christina Luke, Ph.D.

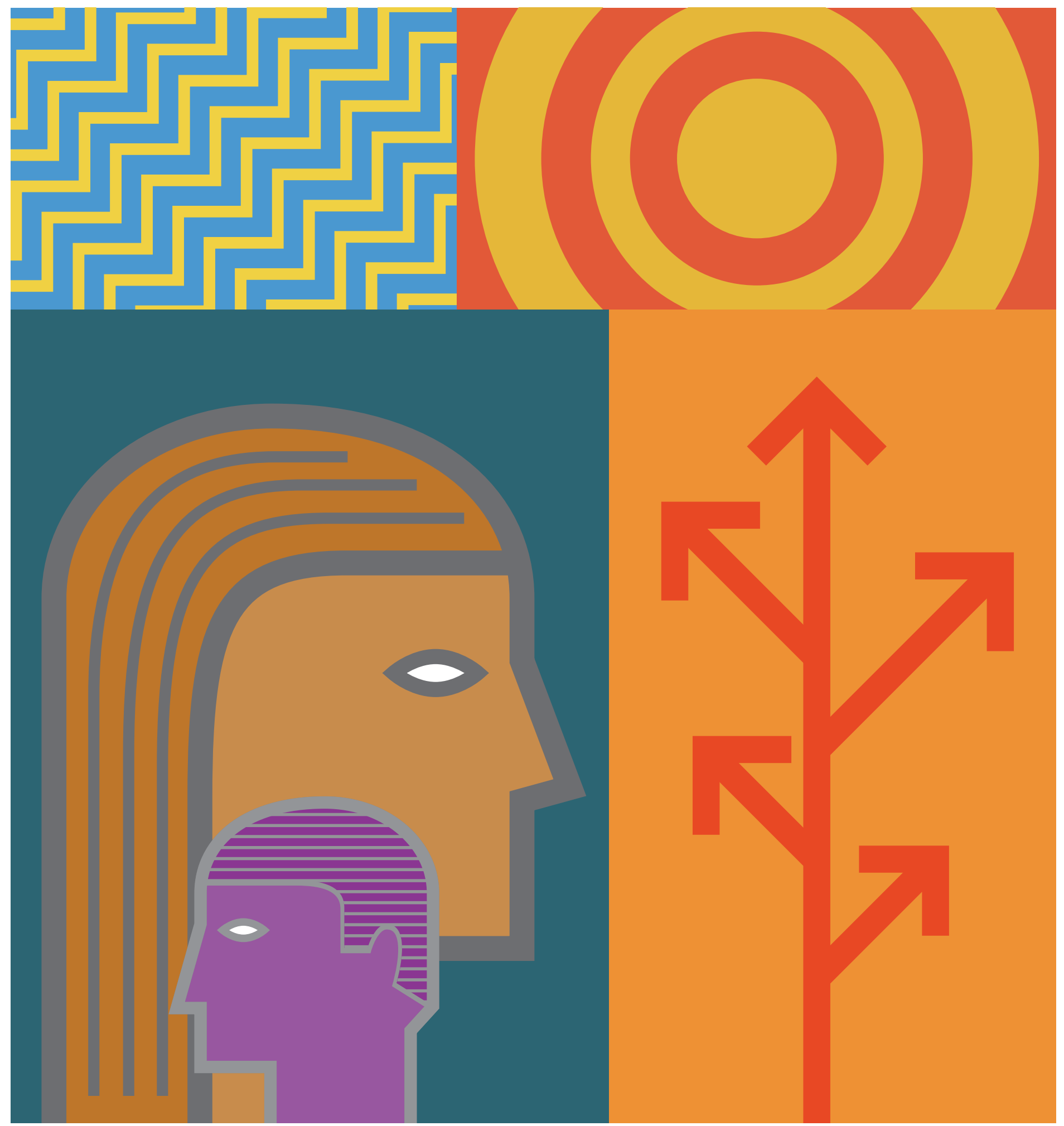




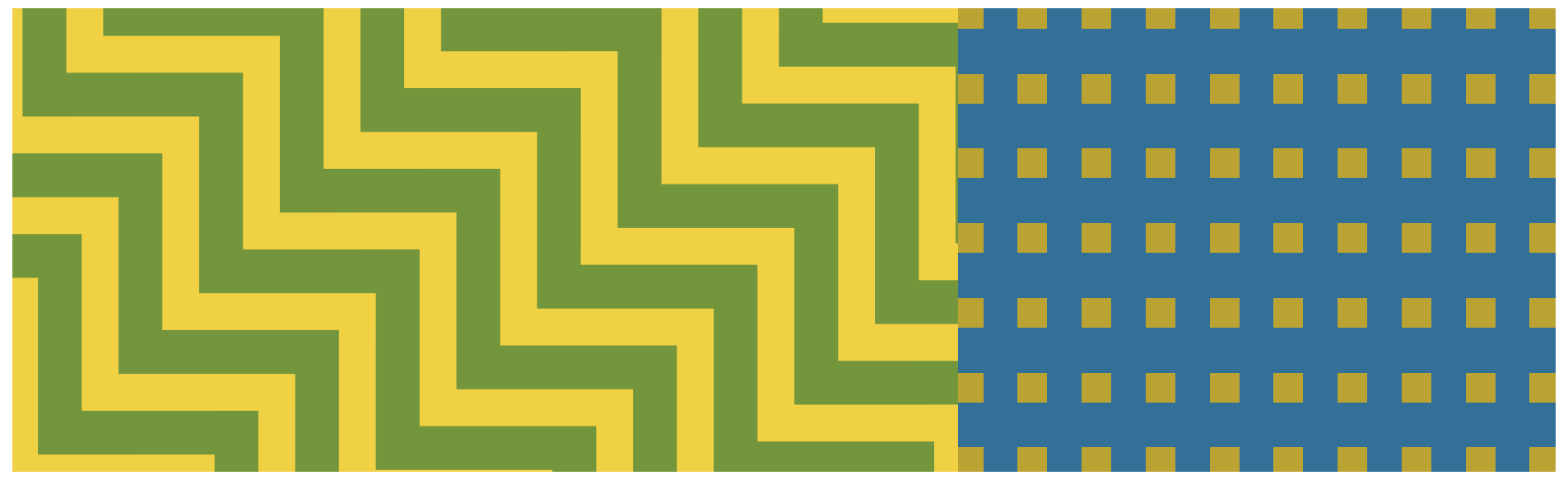

\section{Table of Contents}

Executive Summary $\ldots \ldots \ldots \ldots \ldots$

Goals and Purpose . . . . . . . . . . . . .4

Methods . . . . . . . . . . . . . . . . . .

Respondent Profile. . . . . . . . . . . . . . . .

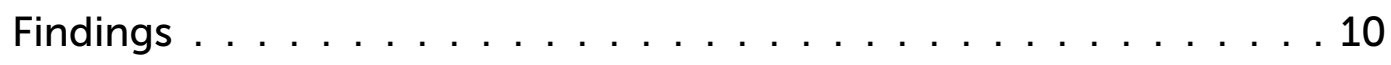

Conclusions and Recommendations . . . . . . . . . . . 19

About the Organizations that Partnered to

Produce this Report . . . . . . . . . . . . . . . . . . 21

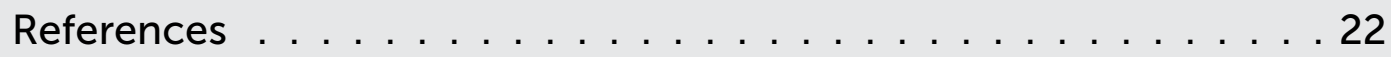




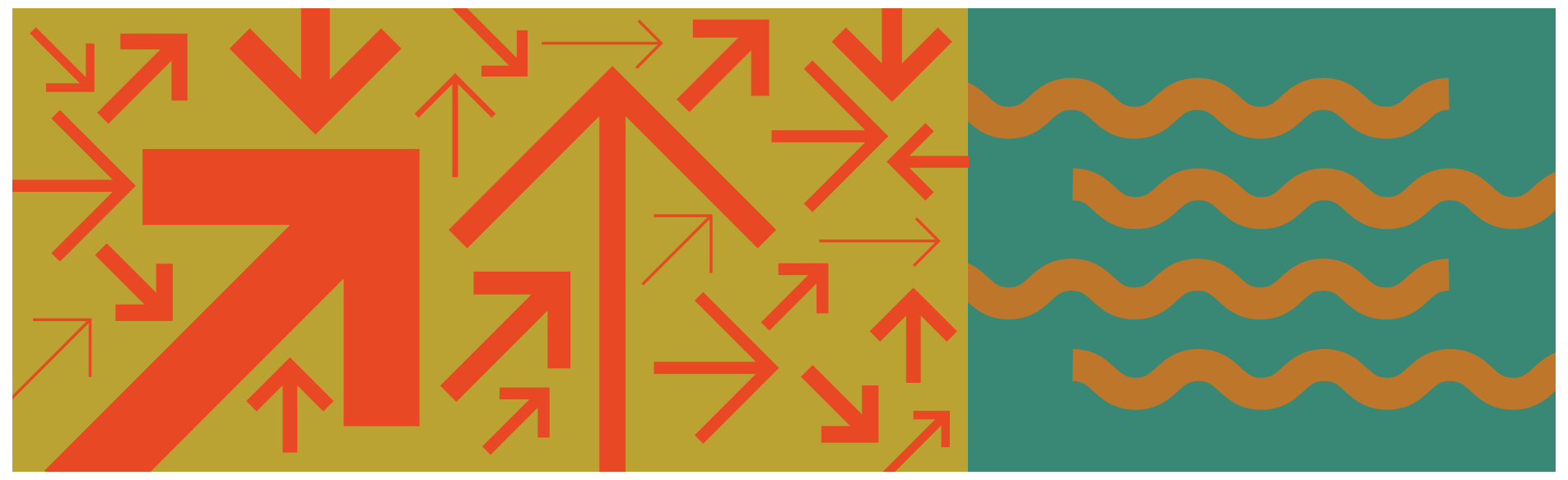

\section{Executive Summary}

Teacher quality is one of the most important factors that contributes to student success. There is a growing body of research that points to coaching as an effective way to support teacher growth. As such, coaching is becoming more prevalent in schools and districts in the U.S., and districts are increasingly using federal, state, and local funds to support coaches and coaching programs.

Given our collective commitment to coaching, Digital Promise, Learning Forward, and Google partnered to provide insights based on a national survey of coaches, teachers, and administrators currently engaged in coaching. From this survey, we have identified several recommendations for the adoption and sustainability of high-quality coaching.

In the report that follows, we share findings on coach workload, the coach-teacher relationship, the use of technology in coaching, professional support for coaches, and funding for coaches. It is promising that $\mathbf{8 3}$ percent

\section{of respondents to the national survey are engaged in coaching in their} school or district. Given that coaching is increasingly common, we focused on opportunities to improve the value and impact of coaching, such as managing coach workload, increasing the duration and frequency of coach time with teachers, and supporting teachers in using technology for student learning. For many of these recommendations, professional development for coaches can help. There is also a need to increase the availability and sustainability of funding for coaches, which is an issue that Digital Promise, Learning Forward, and Google are committed to exploring further in future publications. 


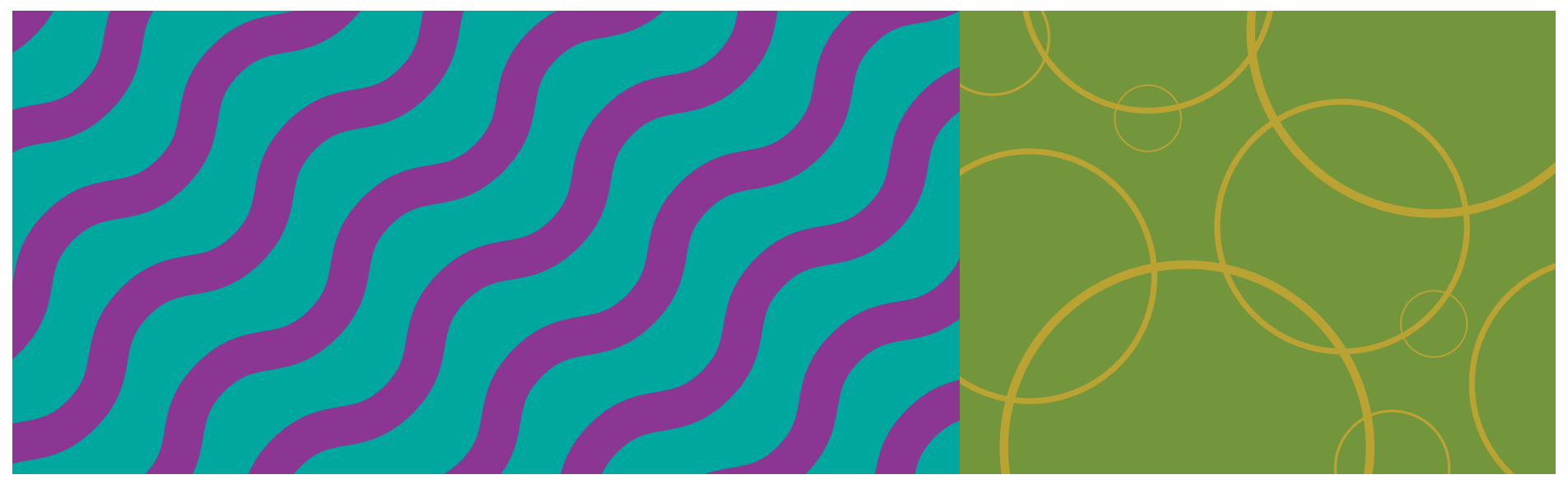

\section{Goals and Purpose}

\section{Background}

As the world continues to change, it is important to provide opportunities for students to deeply engage in their learning while using technology in ways that support digital learning equity. Digital Promise's principles for Powerful Learning guide educators to design learning experiences that engage the hearts and minds of learners. Powerful Learning is personal and accessible, authentic and challenging, collaborative and connected, and inquisitive and reflective.

Powerful Learning experiences are important for students as well as educators. It is equally important that educators have access to Powerful Learning experiences themselves, and that they know how to create those experiences for their students. One of the most powerful and effective forms of professional learning for educators-and for professionals in many fields-is coaching. When it comes to knowledge and skill gains, and application of the new knowledge and skills to practice, the most impactful professional development element is coaching (See Table 1, Joyce \& Showers, 2002). And when implemented effectively, coaching meets all the criteria for a Powerful Learning experience. It is personalized, authentic to the needs of the educator, collaborative, and inquiry-based. 


\section{Table 1. Teacher professional development outcomes}

\begin{tabular}{|l|l|l|l|}
\hline $\begin{array}{l}\text { Professional development } \\
\text { elements }\end{array}$ & $\begin{array}{l}\text { Knowledge } \\
\text { level } \\
\text { (\% understanding } \\
\text { content) }\end{array}$ & $\begin{array}{l}\text { Skill } \\
\text { attainment } \\
\text { (\% demonstrating } \\
\text { proficiency in } \\
\text { instructional } \\
\text { practices) }\end{array}$ & $\begin{array}{l}\text { Transfer to } \\
\text { practice } \\
\text { (\% regularly } \\
\text { implementing } \\
\text { instructional practices } \\
\text { in the classroom) }\end{array}$ \\
\hline $\begin{array}{l}\text { Theory } \\
\text { (e.g., presenter explains content-what it is, } \\
\text { why it is important, and how to teach it) }\end{array}$ & $10 \%$ & $\mathbf{5 \%}$ & $0 \%$ \\
\hline $\begin{array}{l}\text { Demonstration } \\
\text { (e.g., presenter models instructional } \\
\text { practices) }\end{array}$ & $30 \%$ & $\mathbf{2 0 \%}$ & $\mathbf{0 \%}$ \\
\hline $\begin{array}{l}\text { Practice } \\
\text { (e.g., participants implement instructional } \\
\text { practices during the session) }\end{array}$ & $\mathbf{6 0 \%}$ & $\mathbf{6 0 \%}$ & $\mathbf{5 \%}$ \\
\hline $\begin{array}{l}\text { Coaching } \\
\text { (e.g., participants receive ongoing support } \\
\text { and guidance when they return to the } \\
\text { classroom) }\end{array}$ & $\mathbf{9 5 \%}$ & $\mathbf{9 5 \%}$ & $\mathbf{9 9 \%}$ \\
\hline
\end{tabular}

\section{Dynamic Learning Project}

In 2017, Digital Promise partnered with Google and EdTechTeam on the Dynamic Learning Project (DLP), an instructional coaching program with the goal of increasing educational equity and the impactful use of technology. The DLP aimed to provide educators with powerful learning experiences via coaching and equip educators to create Powerful Learning experiences for their students. Since its launch, the DLP has reached 160 schools in 32 school districts across 10 states-Alabama, Arkansas, California, New York, North Carolina, Pennsylvania, South Carolina, Washington, Wisconsin, and Texas-to support school-based instructional technology coaches with mentoring, professional development, and continuous improvement data for coaches, principals, and district leaders.

Digital Promise led a corresponding research study to provide formative feedback to coaches and their professional learning mentors, as well as to assess the impact of the Dynamic Learning Project. Key questions focused on the quality of professional learning and the quality of technology implementation among the educators supported by the coaches. During the pilot year, we found that teachers who participated in the DLP used technology more frequently and in more powerful ways with their students. In Year 2. teachers who received DLP coaching reported greater skills and confidence in leveraging technology in their teaching, which resulted in increased student engagement and learning. 
Overall, our findings suggest that Dynamic Learning Project coaching is more than just a promising intervention-it's transforming professional development into a Powerful Learning experience for educators, which translates into educators' abilities to create Powerful Learning experiences for their students.

\section{National Coaching Survey and Report}

Given the impact of coaching found in Dynamic Learning Project schools, we were interested in exploring the overall coaching landscape in the U.S., including access to coaching, the perceived effectiveness of coaching, and the existing financial and professional support for coaches. Our goal in learning more about the coaching landscape in the U.S. is to be able to provide recommendations for the adoption and sustainability of high-quality coaching that supports Powerful Learning.

In order to gain insight into a robust national network of coaches, educators, and administrators committed to professional learning, Digital Promise partnered with Learning Forward to design and distribute a national survey. Learning Forward is a professional association that supports more than 44,000 educators and education leaders in planning, implementing, and measuring high-quality professional learning. Learning Forward works at all levels of the education system to achieve our vision: Equity and excellence in teaching and learning.

This report will share information about the state of instructional coaching in the U.S. and provide recommendations based on our findings that we hope will enable education leaders to more effectively provide coaches with funding and professional support. 


\section{Methods}

In 2019, Digital Promise and Learning Forward collaborated to design a national survey using validated survey questions from the Dynamic Learning Project. Leveraging our networks of educators and education leaders, both Learning Forward and Digital Promise shared the online survey link with our members via email on October 2, 2019. We sent two reminders and closed the survey on October 22, 2019, after receiving 1,246 responses. Respondents were offered a chance to be selected to receive a modest incentive for completing the survey.

Using Qualtrics, Digital Promise research staff cleaned and analyzed the data. All survey respondents reported on the demographic composition of their school sites, but those respondents who were not currently engaged in coaching in their school or district (13.7 percent of all respondents) were not included in the analysis below. The demographics of the respondents not engaged in coaching did not significantly differ from the overall population. The remaining responses were analyzed by role (educator, coach, school leader, district leader) and by site type (school- or district-based).

\section{Respondent Profile}

Overall, 1,038 respondents ( 83 percent) reported being currently engaged in coaching in their school or district. These respondents are distributed across all 50 states (see Figure 1).

Figure 1: Regional Breakdown of Respondents

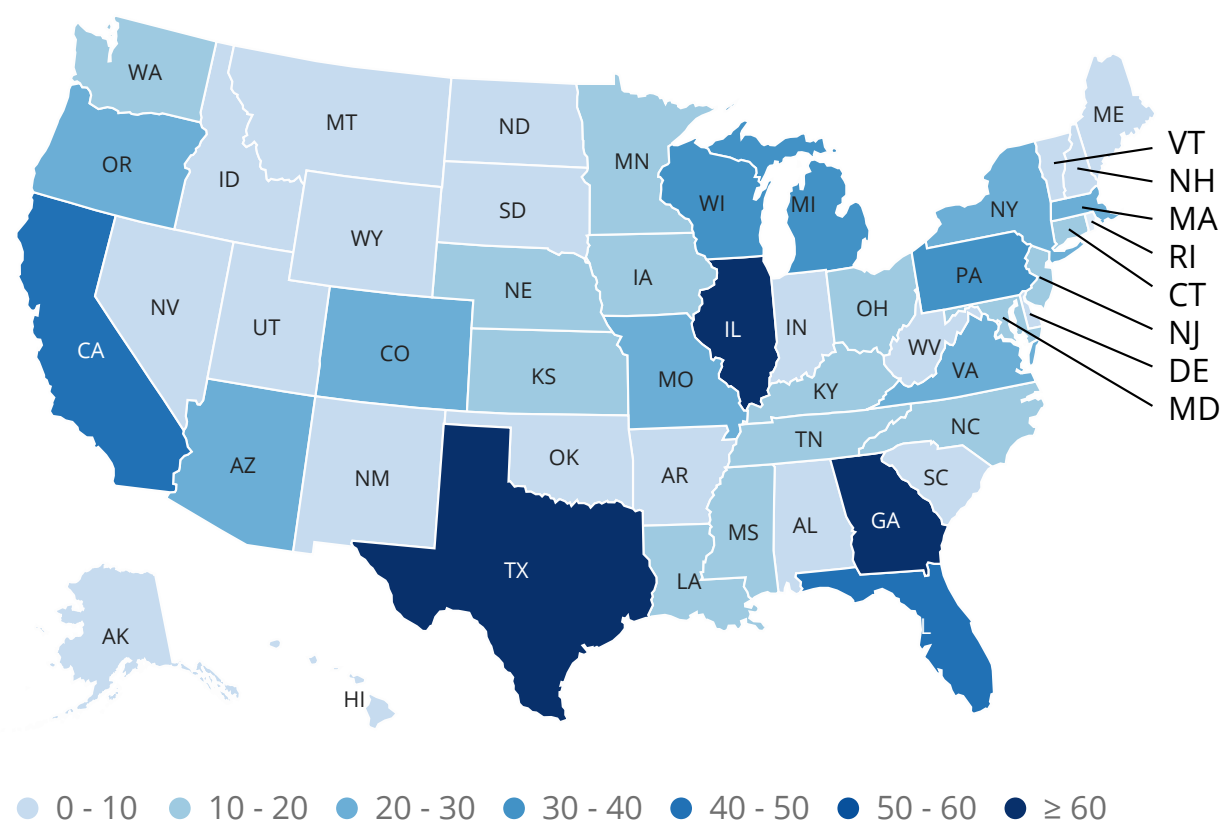


The most responses came from Illinois ( $N=77)$, Georgia $(N=75)$, and Texas $(N=69)$. Of those who are engaged in coaching, slightly more serve in school-based roles (55.1 percent) than district-based roles (44.9 percent). The majority of respondents are coaches, followed by administrators, educators, and "other," which includes curriculum coordinators, instructional specialists, and special education support staff (see Figure 2).

Figure 2: Roles of Respondents with Access to Coaching Programs

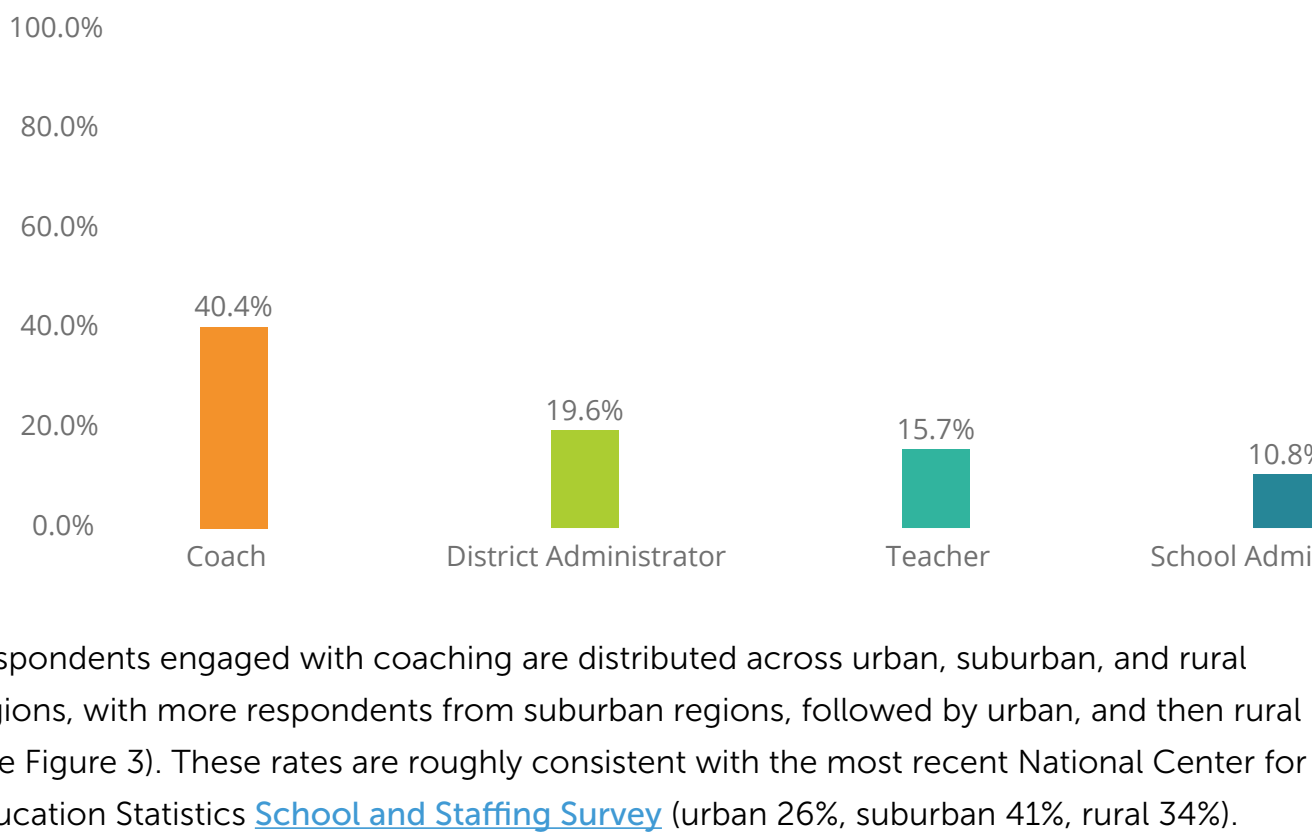

Figure 3: Urbanicity of Respondents

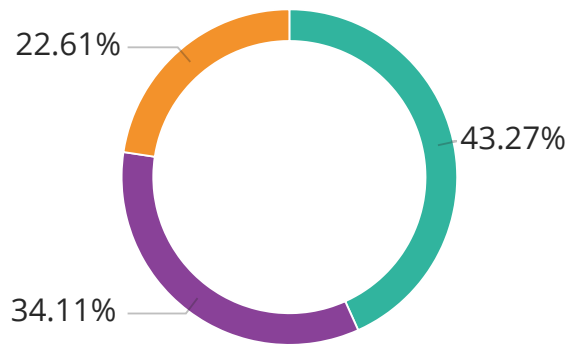

- Suburban • Urban - Rural 
More than two-thirds of the respondents are from schools or districts with more than 40 percent of students qualifying for free and reduced-price lunch (see Figure 4). The same School and Staffing Survey estimates that roughly 45 percent of schools fell into this category in 2011-12, so this survey's respondents may reflect more schools leveraging Title I federal dollars than the national average.

Figure 4: Percentage of Respondents' Students Qualifying for Free and Reduced-Price Lunch

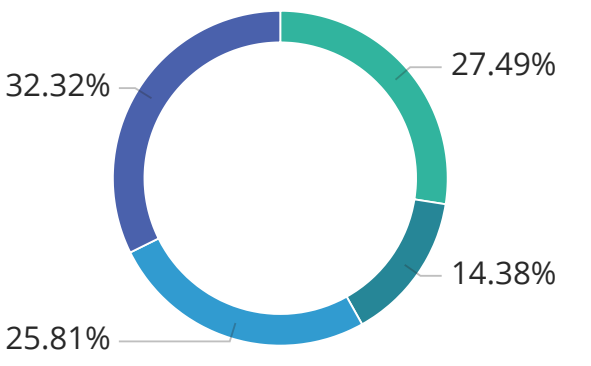

- Less than $40 \%$ - Between $40 \%$ and $50 \%$ - Between $50 \%$ and $75 \%$ - More than $75 \%$

The overwhelming majority of respondents are female (see Figure 5) and have more than 15 years of experience in K-12 education (see Figure 6). Respondents are distributed roughly evenly across grade levels.

Figure 5: Gender of Respondents

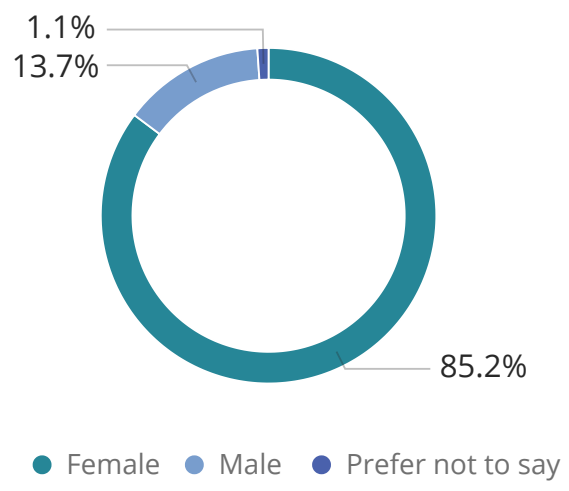

Figure 6: Respondents' Experience in K-12 Education

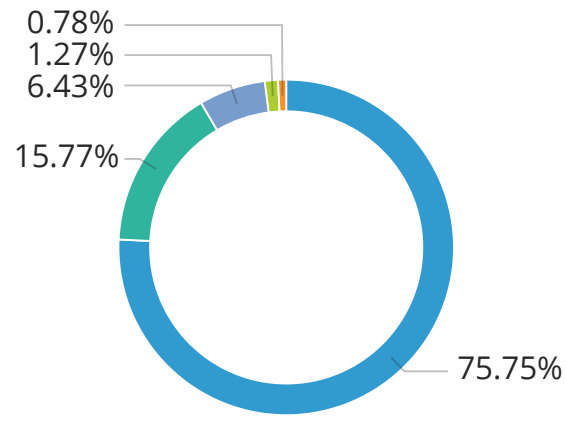

- More than 15 years 11-15 years 5-10 years 2-4 years Less than 2 years 


\section{Findings}

\section{Coach Workload}

While the prevalence of coaching across the country is promising, insights about the roles coaches juggle and the number of educators they support suggest a very full workload for coaches that may jeopardize the positive impact of coaching. Many coaches reported serving in other roles in addition to their role as a coach. Forty percent of school-based coaches are also classroom teachers, compared to only 17 percent of district-based coach respondents (see Figures 7 and 8 ). The majority of coaches support several teachers at a time; nearly half of school-based coaches serve more than 16 teachers at one time, while 65 percent of district-based coaches serve more than 16 teachers concurrently (see Figure 9). At both the school and district level, the data suggests that coaches are often expected to wear multiple hats and support many teachers at the same time.

Figure 7: Other Roles Held By School-Based Coaches

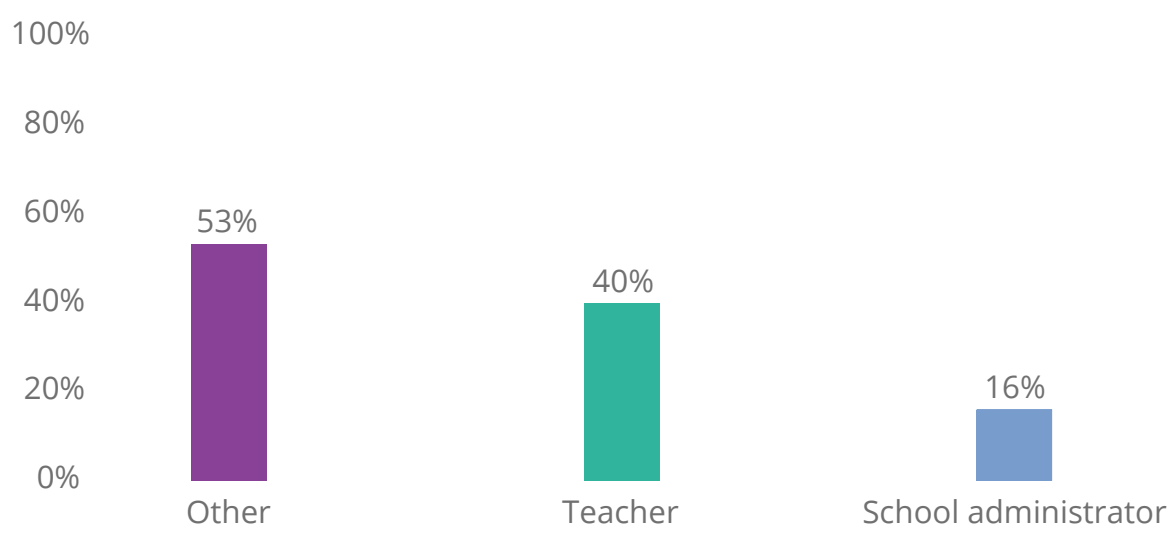

Figure 8: Other Roles Held By District-Based Coaches

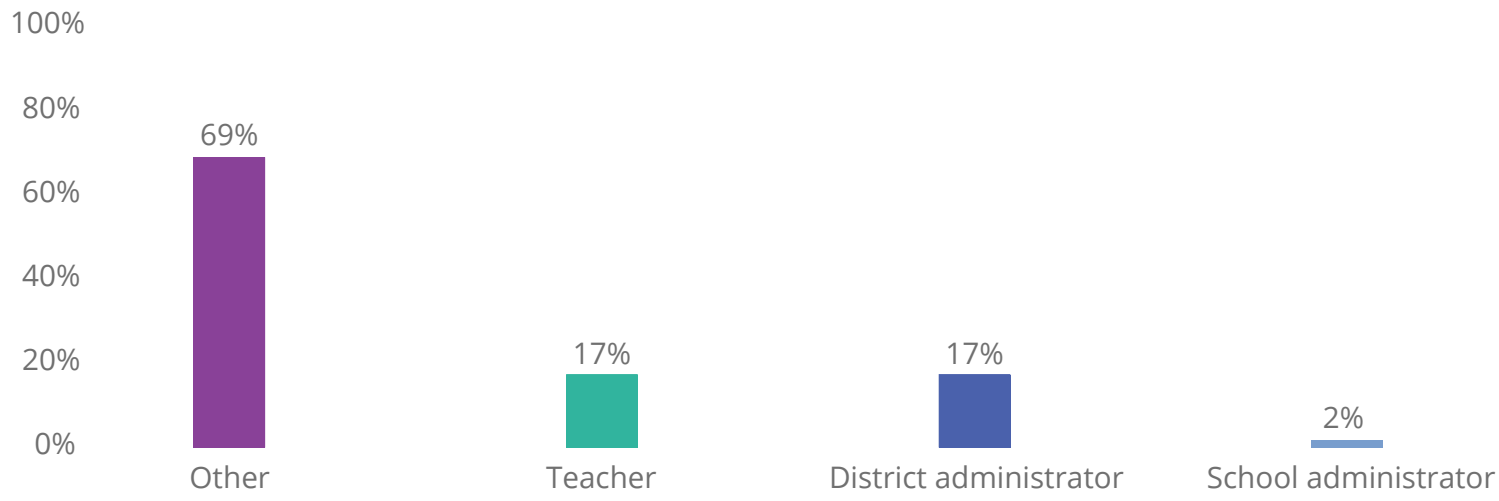


Figure 9: Number of Teachers Served by Coaches

Number of Teachers Typically Served by School-Based Coaches

$10 \%$

$20 \%$

$23 \%$

- 1 to $5 \bullet 6$ to $10 \bullet 11$ to $15 \bullet 16$ to $20 \bullet$ Other

Number of Teachers Typically Served by District-Based Coaches

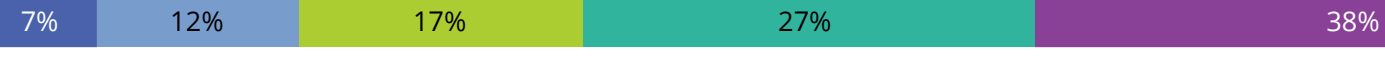

- 1 to $5 \bullet 6$ to $10 \bullet 11$ to $15 \bullet 16$ to $20 \bullet$ Other

\section{Coach-Teacher Relationship}

Teacher Perceived Value and Impact of Coaching

Learning Forward and others have studied the relationship between professional learning experiences and educator satisfaction and found that meaningful and engaging professional learning experiences can help support educator job satisfaction, particularly when those experiences support collegiality, reflection, and collaboration (Learning Forward, 2012).

\section{The majority of educator respondents in the national coaching survey find coaching to} be a valuable and impactful form of professional development. More than three-quarters of educator respondents find coaching valuable, ranging from somewhat to highly valuable (see Figure 10). A similar percentage of educator respondents find coaching to have a positive impact on their practice (see Figure 11). These findings suggest that coaching may lead to other positive outcomes, such as increased teacher job satisfaction and retention.

Figure 10: Educator-Reported Value of Coaching

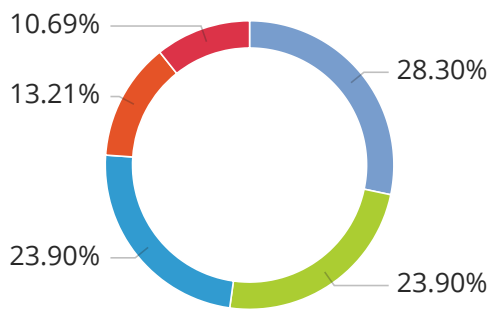

- Very valuable Somewhat valuable Highly valuable Slightly valuable $\bullet$ Not valuable

Figure 11: Educator-Reported Positive Impact of Coaching

$\begin{array}{lllll}9 \% & 19 \% & 23 \% & 27 \% & 23 \%\end{array}$

- No positive impact $\bullet$ To a small extent $\bullet$ To a moderate extent $\bullet$ To a large extent $\bullet$ To a great extent 


\section{Role of Technology in Coaching}

In the past 10 years, the first digital divide across U.S. public schools has narrowed significantly-more than 90 percent of schools now have access to the internet. At the same time, a new divide emerged - the digital use divide-which is fueled by major differences in how teachers and students use technology. The digital use divide underscores the importance of impactful technology use. Impactful technology use helps enable Powerful Learning and is defined by six criteria: student ability to select relevant technology tools and to use technology for collaboration, communication, critical thinking, creativity and innovation, and agency. Coaching has been shown to help increase impactful use of technology. Research on the Dynamic Learning Project, a technology coaching program, found that more coached teachers, compared to non-coached teachers, report students use technology to develop these 21st century skills at least monthly. Also, compared to non-coached teachers, coached teachers reported greater impact on student engagement and learning as a result of their impactful technology use (Bakhshaei, Hardy, Ravitz, \& Seylar, 2019).

Despite the previous research on the importance of coaching for impactful technology use, nearly 40 percent fewer teachers than coaches report in the national coaching survey that technology is used to facilitate the coach's work, support the educator's learning, and support educators in using technology with students for learning (see Figures 12 and 13). The 45 percent difference between coach and teacher responses to whether the coach supports the teacher in using technology with students is a stark disparity; it suggests that there is an opportunity for coaches to devote more time to supporting teachers in using technology for student learning, which could lead to increased impactful use of technology by students and increased student engagement and learning.

Figure 12: How Teachers Report Coach Use of Technology
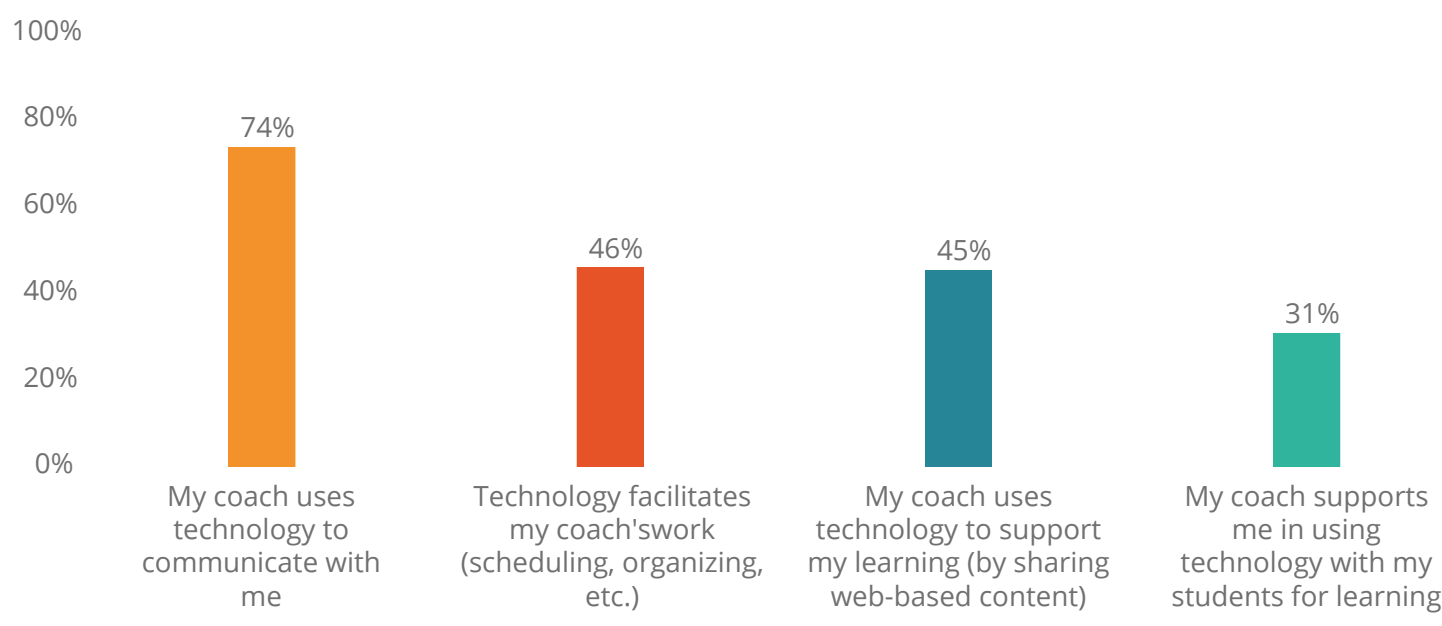

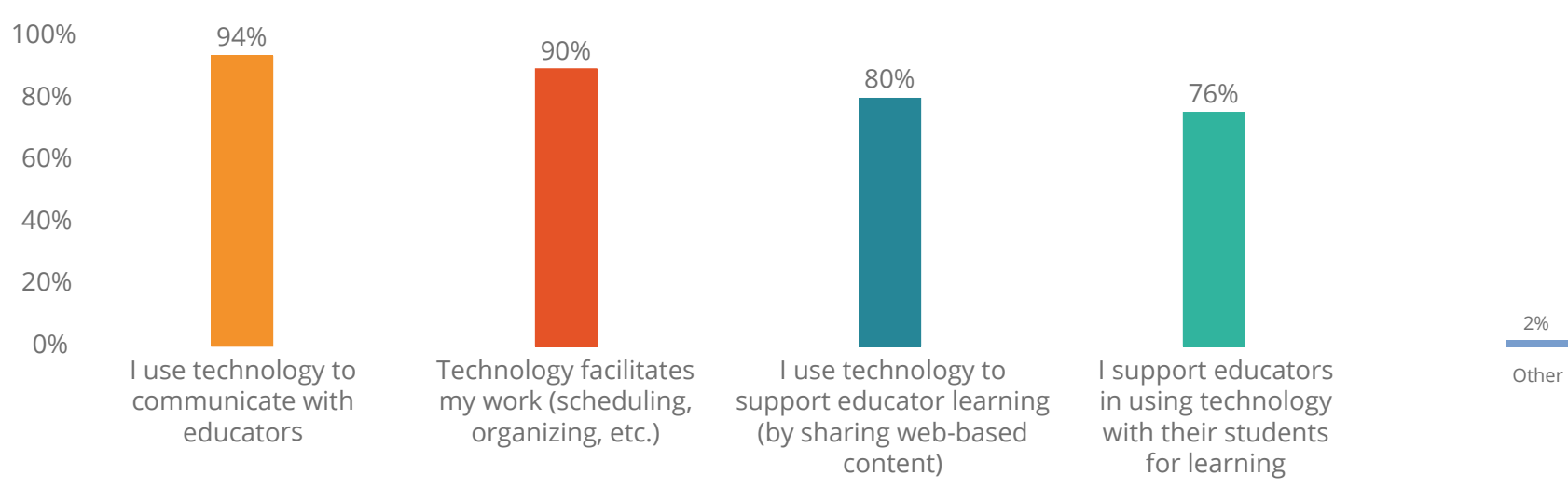

Teachers who find coaching valuable report that their coach uses technology at higher rates than teachers who do not find coaching valuable (see Figures 14 and 15). Increased technology use by coaches and increased support for teacher technology use could make coaching more valuable to teachers. It's possible that there is a greater need for coaching programs like the Dynamic Learning Project that help coaches improve their ability to use technology themselves and support teachers in their ability to use technology.

Figure 14: How Technology is Used with Teachers Who Find Coaching Valuable
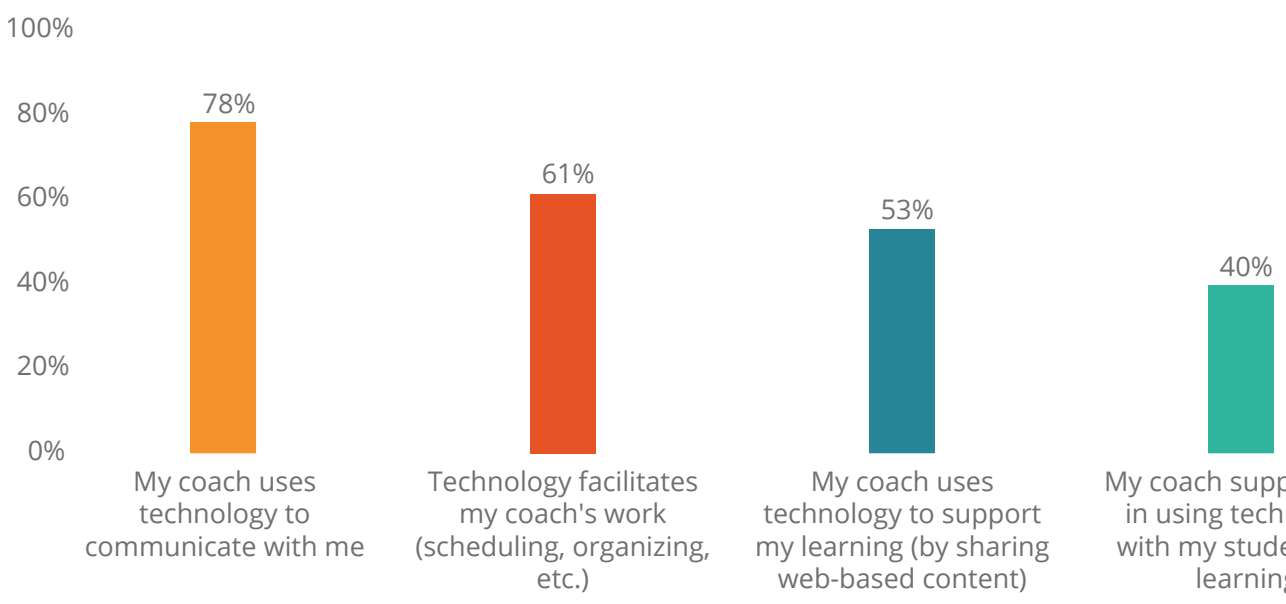

My coach supports me in using technology with my students for learning

Figure 15: How Technology is Used with Teachers Who Do Not Find Coaching Valuable
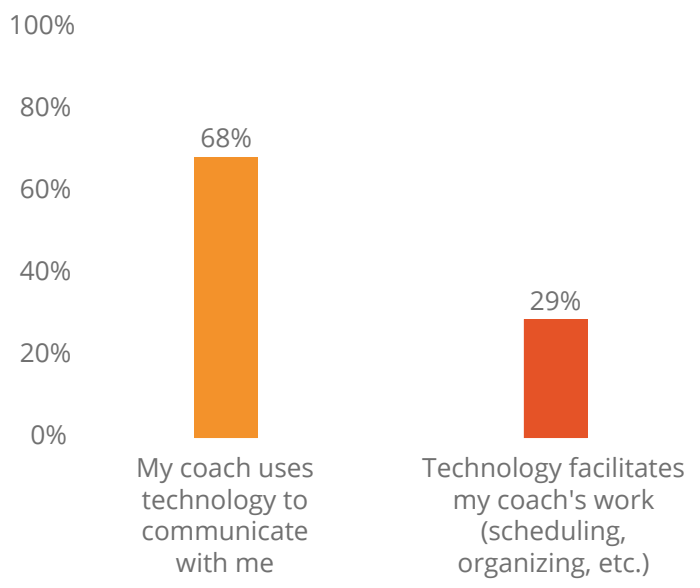

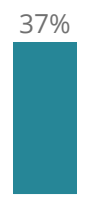

My coach uses technology to support my learning (by sharing web-based content)

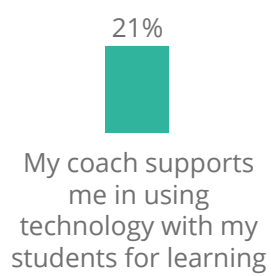

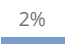

Other$$
\text { (and }
$$ 


\section{Frequency and Duration of Coaching}

According to Dynamic Learning Project research, effective coaching is sustained over time. Coaching should involve continuous cycles of action and reflection. Literature suggests that 20 hours of contact time results in better student performance. Spacing the contact is important, too (Garet, Porter, Desimone, Birman, \& Yoon, 2001). In a Dynamic Learning Project study, researchers found that the more time a teacher spent with their coach, the greater their professional growth (Bakhshaei, Hardy, Ravitz, \& Seylar, 2019).

The majority of all teacher respondents in the national coaching survey spend less than 30 minutes with their coach (see Figure 16). However, the majority of teacher respondents who find coaching valuable spend at least 30-60 minutes with their coach (see Figure 16).

Figure 16: Average Time Teachers Spent With Coaches, By Valuation of Coaching

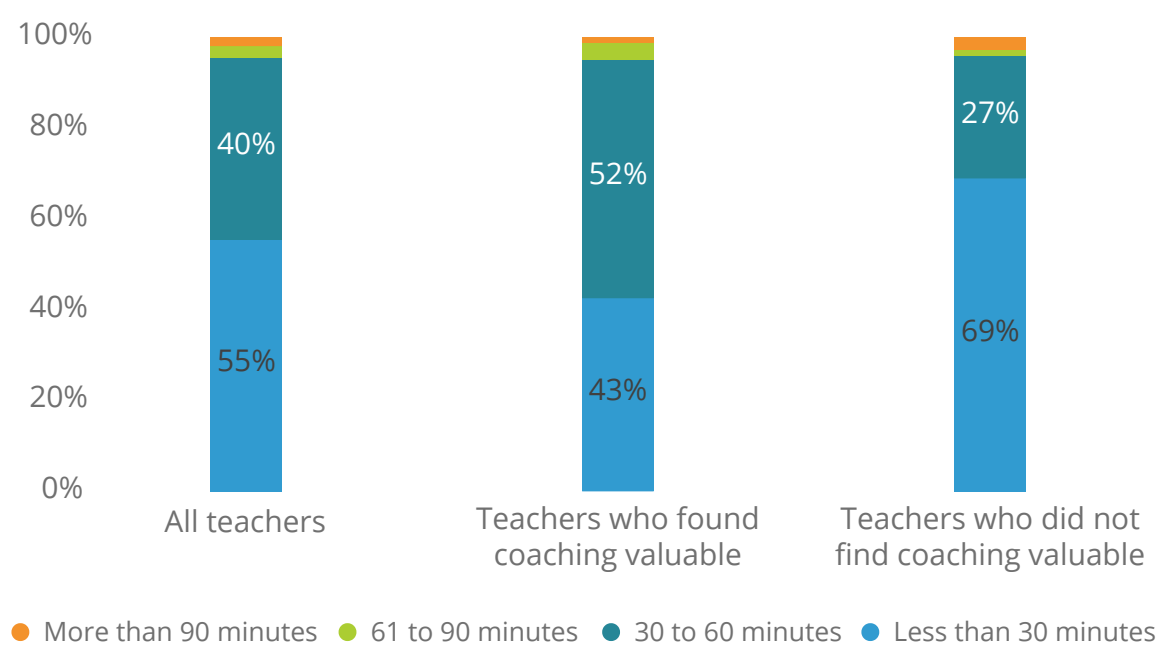


Moreover, while fewer than half of teachers meet with their coach at least biweekly, 61 percent of teachers who find coaching valuable have at least biweekly meetings with their coaches (See Figure 17). On average, teachers who spend more time with their coach rate their coaching as very or highly valuable (see Figure 17).

Figure 17: Frequency of Teacher Meetings with Coaches, By Valuation of Coaching

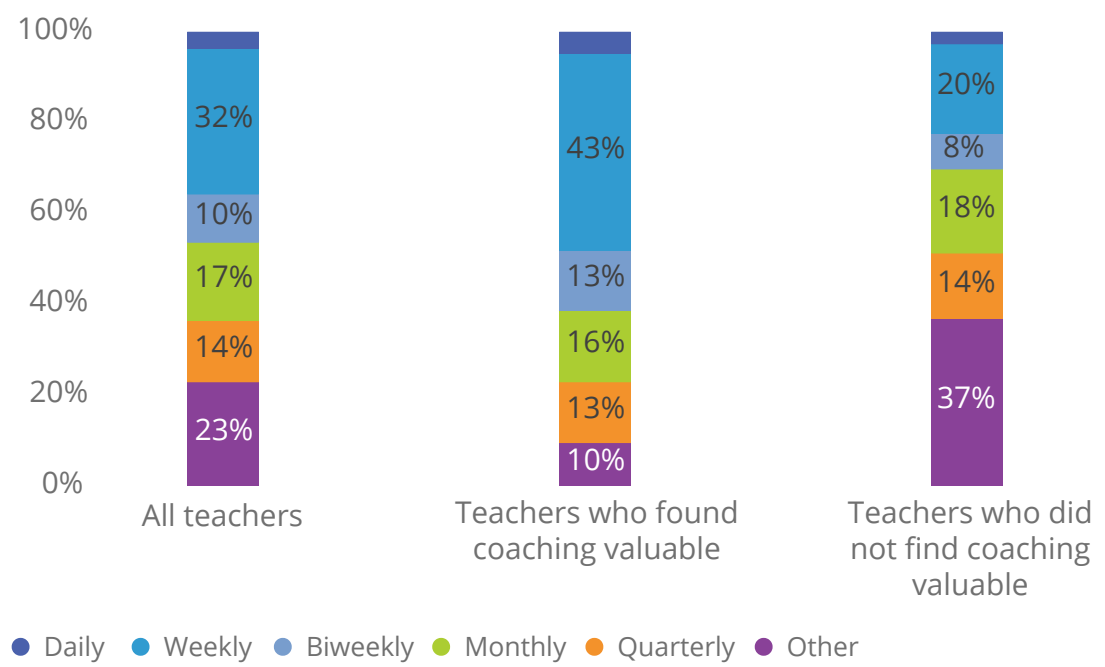

\section{Support for Coaches}

\section{Professional Development Support}

Professional learning is important not only for educators but also for coaches. Coaches, like any professional, need support building their skills. Over the course of the 2018-2019 school year, the number of coaches receiving professional development support from the Dynamic Learning Project who rated their coaching skills as strong or very strong increased by 30 percent from the beginning of the year to the end of the year (Bakhshaei, Hardy, Ravitz, \& Seylar, 2019). This suggests that coaches who receive high-quality professional development are able to improve their practice.

In the national coaching survey, the majority of coaches reported that their professional learning is effective. Almost 80 percent of coaches say their professional development is either very effective or somewhat effective (see Figure 18).

Figure 18: Coaches' Evaluation of Their Professional Development

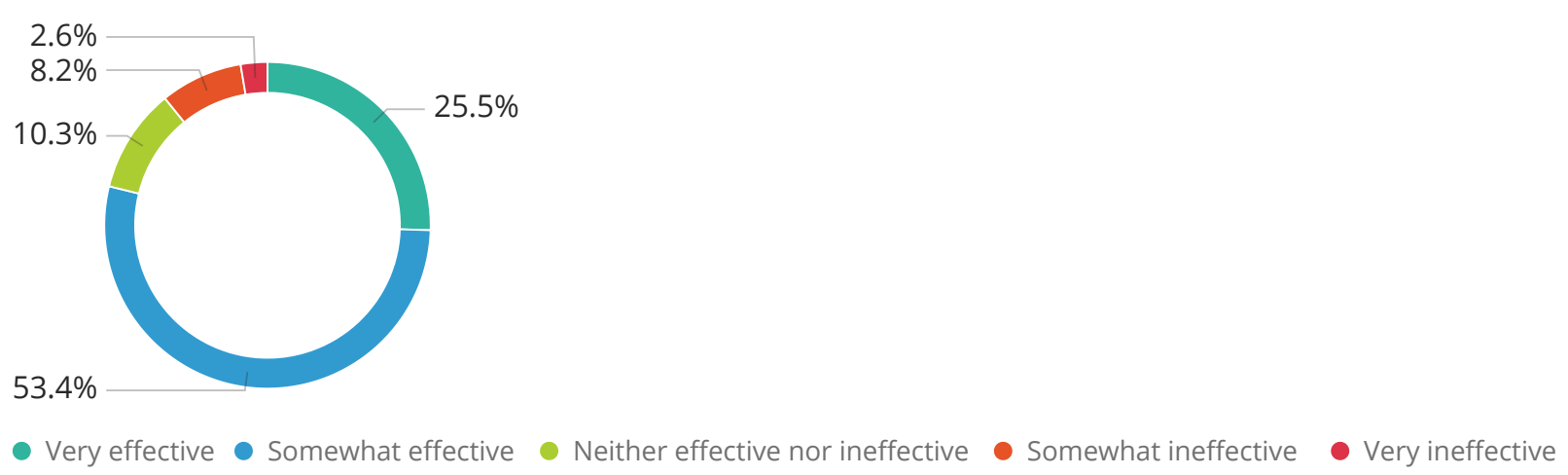


According to school and district leaders, professional development for school-based coaches is often timely and tailored to the coaches' needs (see Figures 19 and 20).

Figure 19: Qualities fo Coach Professional Development According to School Administrators

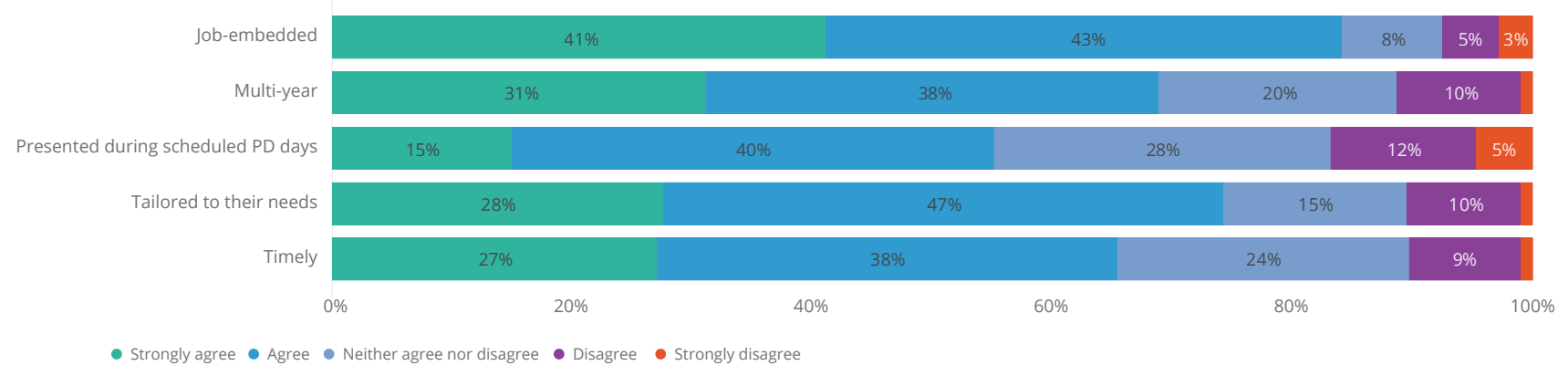

Figure 20: Qualities of Coach Professional Development According to District Administrators

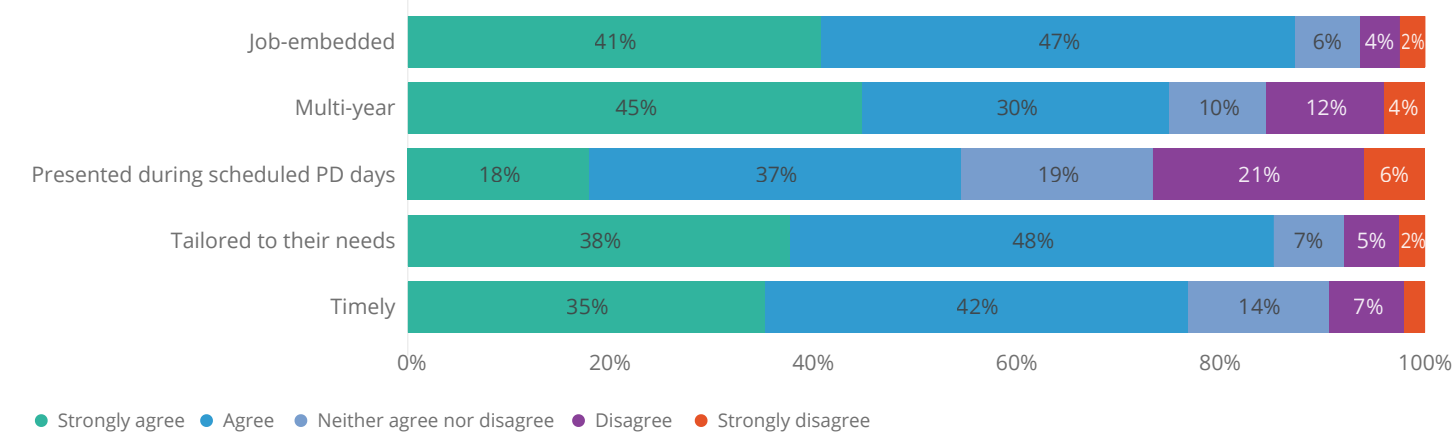

Eighty-four percent of school-based administrators and 74 percent of leaders at the district level agree or strongly agree that professional learning for coaches is tailored to coaches' needs. More than two-thirds of all administrators agree or strongly agree that professional learning for coaches is timely.

The majority of professional development content for coaches spans multiple school years. Nearly three-quarters of district-based administrators and 68 percent of school-based administrators agree or strongly agree that professional learning for coaches is multi-year (see Figures 19 and 20). It is promising that coaches see continuity in professional learning content year over year. 
Coaches are almost always evaluated by district administrator and/or principal observation.

Teachers contributing feedback to coach evaluation is not as common (see Figure 21). According to Dynamic Learning Project research, one of the components of effective coaching is that it's personalized (Bakhshaei, Hardy, Ravitz, \& Seylar, 2019). In order to make coaching more personalized, teachers should be included in the evaluation of coaches more often.

Figure 21: Sources of Evaluation for Coaches

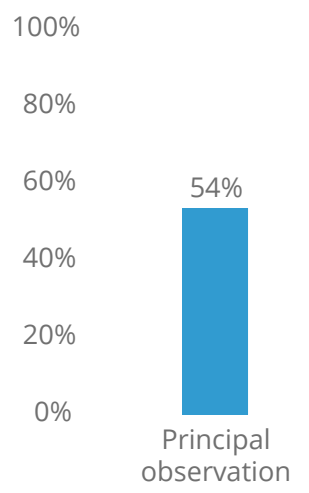

\section{Funding and Sustainability}

On average, district-based coaches are funded over multiple years slightly more than school-based coaches. However, fewer than half of coaches overall are funded at consistent rates. Forty-three percent of district-based administrators reported that coaches are funded multi-year, compared to 37 percent of school-based administrators (see Figure 22).

\section{Figure 22: Funding Timeline of School and District Leaders' Coaches}

District-based coaches

School-based coaches
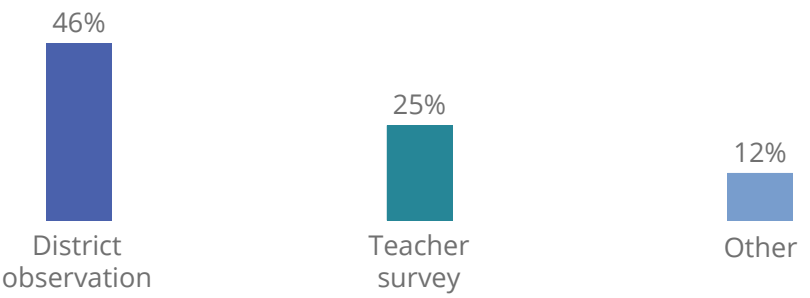

- Year-to-year Multi-year @ Other

Coaches are funded primarily by Title II federal funds, which are designated to support preparing, training, and recruiting high-quality teachers and principals (U.S. Department of Education, 2004), as well as by local and state formula funding. Other sources of funding include school staff budget, teacher salary, and Title I federal funds, which provide financial assistance to local educational agencies for children from low-income families to help ensure that all children meet challenging state academic standards (U.S. Department of Education, 2018). 
$100 \%$

$80 \%$

$60 \%$

$55 \%$

$40 \%$

20\% $\quad 5 \%$

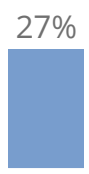

Title II funds
$29 \%$

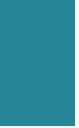

Formula funding

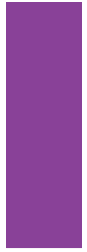

Other

Figure 24: Funding Sources for District-based Coaches

$100 \%$

$80 \%$

$60 \%$

$40 \%$

$20 \%$

$4 \%$
Philanthropic grant
funds

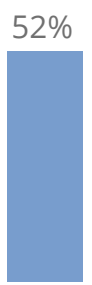

Title II funds

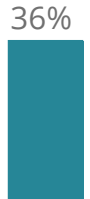

Formula funding
$57 \%$

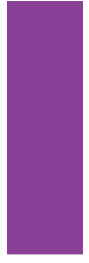

Other 


\section{Conclusions and Recommendations}

As a result of surveying a national sample of coaches, teachers, and district administrators engaged in coaching in their schools and districts, we gained a better understanding of the state of coaching in the U.S., including the conditions under which coaches are working, perceived educator value of coaching, use of technology in coaching, and professional development and funding support for coaches. These findings led to the following recommendations and next steps.

- Coach workload: Coaches serve in multiple roles; 40 percent of school-based coaches are also still part-time classroom teachers. They also support large caseloads of educators; more than 50 percent of school- and district-based coaches support 16 or more teachers at once. This may create challenges for the coach, including preventing them from devoting sufficient time to each teacher. Principals and district administrators can help support coaches by monitoring their workload and protecting their time so they can have the greatest impact.

- Coach-teacher relationship: The majority of educators find coaching valuable. Those educators who feel most strongly about the value of coaching tend to work with their coach more frequently and spend more time with their coach at each meeting. Ideally, coaches would be able to spend at least 30 minutes with teachers at biweekly intervals to see the greatest value (Bakhshaei, Hardy, Ravitz, \& Seylar, 2019).

- Coach use of technology: Coaches and teachers have different perceptions about how coaches are using technology in their practice. Coaches report using technology more frequently with teachers and for more use cases than teachers do. There may be opportunities to focus coaching time on the use of technology with students, particularly since that focus has been impactful for educators involved in coaching initiatives like the Dynamic Learning Project. Additionally, given that teachers rated coach use of technology to facilitate communication fairly low, coaches may want to consider leveraging technology, such as chat platforms and video conferencing, to provide more personalized and timely support for teachers.

- Coach professional development: Coaches are generally satisfied with the professional development support they receive, though coaches based in schools gave slightly more favorable ratings than their district-based counterparts. While coaching is a valuable professional development experience for educators, providing meaningful support to coaches is also important.

- Funding for coaches: District-based coaches may benefit from more secure, multiyear funding than school-based coaches, but fewer than half of coaches overall are funded at consistent rates. Longer-term investments in coaching could support comprehensive programs and maintain continuity from year to year. Additionally, federal and state funds dedicated specifically to coaching could make implementing this high-impact professional learning strategy easier to sustain. 
In follow-up to this report, we plan to work with districts, state and federal governments, and organizations focused on professional development to further explore and advocate for the conditions and policies necessary for the adoption and sustainability of high-quality coaching that supports Powerful Learning.

Additionally, Digital Promise plans to further explore some of the questions raised by this survey, including

- the availability and sustainability of funding for coaches,

- the barriers that exist in schools and districts that reported not being currently engaged in coaching, and

- coach access to programs that provide professional development and support.

Digital Promise, Learning Forward, and Google hope that this report sparks further research, conversation, and collaboration. To learn more about Digital Promise's research on coaching, visit our website and sign up to receive our Action Report newsletter for updates on our work to support access to high-quality coaching for teachers.

To learn more about Learning Forward's research on coaching, visit its website and check out its publications on coaching, including Taking the Lead: New Roles for Teachers and School-Based Coaches, 2nd Edition and Coaching for Impact. 


\section{About the Organizations that Partnered to Produce this Report}

\section{About Digital Promise}

Digital Promise is a nonprofit organization that builds powerful networks and takes on grand challenges by working at the intersection of researchers, entrepreneurs, and educators. Our vision is that all people, at every stage of their lives, have access to learning experiences that help them acquire the knowledge and skills they need to thrive and continuously learn in an ever-changing world. For more information, visit the Digital Promise website and follow @ DigitalPromise on Twitter for updates.

\section{About Learning Forward}

Learning Forward is a nonprofit, international membership association of learning educators committed to one vision in K-12 education: Equity and excellence in teaching and learning. To realize that vision Learning Forward pursues its mission to build the capacity of leaders to establish and sustain highly effective professional learning. Information about membership, services, and products is available from www.learningforward.org

\section{About Google for Education}

Google is committed to directing our resources-our products, programs, philanthropy, and people-toward making education accessible for everyone. While technology alone won't improve education, we believe it can be a powerful part of the solution, and we want to help ensure that all teachers and students are able to benefit from it. We'll continue working toward a future where every student has access to the skills they'll need and the quality education they deserve. For more information about our work in education, visit edu.google.com and follow along on Twitter at @googleforedu. 


\section{References}

Bakhshaei, M., Hardy, A., Ravitz, J., \& Seylar, J. (2019). Scaling Up Classroom Coaching for Impactful Technology Use. Digital Promise. Retrieved from https://digitalpromise.org/wp-content/uploads/2019/09/DLP_CoachingReport2019.pdf

Garet, M.S., Porter, A.C., Desimone, L., Birman, B.F., \& Yoon, K.S. (2001). What Makes Professional Development Effective? Results From a National Sample of Teachers. American Educational Research Journal Winter 2001, Vol. 38, No. 4, pp. 915-945. Retrieved from https://journals.sagepub.com/doi/pdf/10.3102/00028312038004915

Joyce, B.R., \& Shower, B. (2002). Student Achievement through Staff Development. Association for Supervision and Curriculum Development.

Learning Forward. (2012). Build higher levels of job satisfaction with professional learning. Retrieved from https://learningforward.org/wp-content/uploads/2012/05/build-higher-levels-of-job-satisfaction-presentation.pdf

U.S. Department of Education. (2004). Title II - Preparing, Training, and Recruiting High Quality Teachers and Principals. Retrieved from https://www2.ed.gov/policy/elsec/leg/esea02/pg20.html

U.S. Department of Education. (2018). Improving Basic Programs Operated by Local Educational Agencies (Title I, Part A). Retrieved from https://www2.ed.gov/programs/titleiparta/index.html 